\title{
Leukocyte set points in metabolic disease
}

\section{Justin I. Odegaard ${ }^{1}$ and Ajay Chawla ${ }^{2 *}$}

\author{
Addresses: ${ }^{1}$ Deparment of Pathology, Stanford University School of Medicine, Stanford, CA 94305, USA; ${ }^{2}$ Cardiovascular \\ Research Institute, Departments of Physiology and Medicine, University of California, San Francisco, 94158-9001, USA \\ *Corresponding author: Ajay Chawla (ajay.chawla@ucsf.edu) \\ FI000 Biology Reports 2012, 4:13 (doi:10.34I0/B4-13) \\ This is an open-access article distributed under the terms of the Creative Commons Attribution-Non Commercial License \\ (http://creativecommons.org/licenses/by-nc/3.0/legalcode), which permits unrestricted use, distribution, and reproduction in any medium, \\ provided the original work is properly cited. You may not use this work for commercial purposes. \\ The electronic version of this article is the complete one and can be found at: http://fl000.com/reports/b/4/I3
}

\begin{abstract}
Vertebrate tissues comprise precise admixtures of parenchymal and hematopoietic cells, whose interactions are vital to proper tissue function. By regulating this interaction, vertebrates are able to mitigate environmental stress and coordinate dramatic physiologic adaptations. For instance, under conditions of chronic nutrient excess, leukocyte recruitment and activation increase in an effort to decrease excess nutrient storage and alleviate adipocyte stress. While basal equilibria may be reestablished upon normalization of nutrient intake, a new set point characterized by insulin resistance and chronic inflammation is established if the stress persists. Consequently, although this response is adaptive in settings of acute overfeeding and infection, it has catastrophic health consequences in the modern context of obesity. Understanding how leukocyte set points (numbers and activation status) are established, maintained, and regulated in tissues is, thus, critical to our understanding of, and intervention in, chronic metabolic diseases, such as obesity and diabetes.
\end{abstract}

\section{Introduction}

Obesity and associated health consequences comprise the greatest public health challenge of our time. Worldwide, $\sim 1.5$ billion people tip the scales as overweight, 300-500 million of whom are obese, placing nearly a quarter of humanity at dramatically increased risk for diabetes, cardiovascular disease, and many types of cancer $[1,2]$. While our considerable scientific investments have barely begun to slow the expansion of our waistlines, they have already yielded unexpected physiologic insights, perhaps the greatest of which is the discovery of the unprecedented level of cooperation between parenchymal cells and leukocytes necessary for proper function in metabolic tissues.

For almost two centuries, the stereotyped appearances of basic human tissues have been staples of medical textbooks [3]. Despite this well-worn familiarity, it was not until recently that cellular inventory of these tissues revealed remarkable numbers of macrophages and other leukocytes tucked away among the more familiar parenchymal cells. However, rather than being randomly distributed, these leukocytes were arranged in stereotyped, reproducible patterns that were tissue-specific $[4,5]$. For example, liver samples consistently harbored similar numbers of macrophages (also known as Kupffer cells) arranged in the same peri-sinusoidal pattern, whereas brain tissues demonstrated similarly constant complements of microglia (resident macrophages of the central nervous system). Indeed, macrophage representation is significant and similar ( $5-15 \%)$ across nearly every tissue and remarkably well conserved across vertebrate species $[6,7]$. Perhaps most interesting of all, however, is that depletion of macrophages from any given tissue results not in permanent loss, haphazard recolonization, or encroachment by other leukocyte lineages, but in rapid and precise restoration of the original macrophage complement in both spatial and numerical terms [8].

While the macrophage's infiltrative penchant has long been appreciated, the precision and rigidity of their arrangements in healthy tissues, the conservation of these patterns across vertebrate species, and their rapid and precise re-establishment following depletion suggest 
that specific set points exist for ensuring an appropriate complement of leukocytes in each tissue. Furthermore, the temporal stability and aggressive re-establishment of macrophage-parenchyma relationships suggest that active mechanisms exist to maintain this interaction within specific parameters [7]. Indeed, recent work has begun to unearth the complex recruitment and retention networks dedicated to the maintenance and survival of resident leukocyte/macrophage populations, e.g. recruitment and survival of $\mathrm{CX}_{3} \mathrm{CR} 1^{+}$monocytes by tissue-derived $\mathrm{CX}_{3} \mathrm{CL} 1$ and Csf1 $[4,9]$. Needless to say, such sophisticated arrangements - especially in tissues with little risk of infection - are not easily explained by traditional theories of host defense. Why then would parenchymal cells go to such lengths to accoutre themselves with macrophages? In answer, numerous studies have now demonstrated that resident macrophages shoulder critical, non-immunologic tissue functions: for example, microglia are required for proper synapse formation and function [10], resident intestinal macrophages are necessary to maintain gut epithelial integrity [11], and bone marrow resident macrophages act as critical components of the hematopoietic stem cell niche [12]. Together, these observations suggest that, as a general principle, vertebrate tissues are critically dependent on resident tissue macrophages to perform their primary functions. In this review, we will explore these concepts as they operate within white and brown adipose tissue physiology. Specifically, we will review recent findings demonstrating novel and nonredundant roles for resident leukocytes in adipose tissue metabolism and discuss how alterations in leukocyte "set points" (numbers and activation status) contribute to the pathogenesis of metabolic disease.

\section{Recent advances}

\section{Macrophage activation}

Macrophages comprise a heterogenous and plastic leukocyte lineage $[4,13]$. While their physiologic roles are diverse and, in many instances, poorly-understood, their behavior may be broadly divided into two categories - classical (M1) and alternative (M2) activation - functionally defined by the phenotypes elicited during bacterial and parasitic infections, respectively [14-16]. These macrophage activation programs can be modeled in vitro by stimulation of bone marrow-derived macrophages with interferon- $\gamma($ IFN- $\gamma) /$ lipopolysaccharide (LPS) or interleukin-4 (IL-4), respectively [14]. Such a definition is likely to be an oversimplification of complex in vivo populations $[13,17,18]$; however, it serves as a useful rubric by which to begin to understand in vivo phenomena.

\section{White adipose tissue}

White adipose tissue is the primary site of long-term nutrient storage in vertebrates and the largest endocrine organ in humans, secreting a variety of hormones termed "adipokines" that regulate systemic metabolism [19]. Healthy white adipose tissue is characterized histologically by a predominance of adipocytes admixed with scattered adipose tissue macrophages, eosinophils, and Tregs (regulatory T cells) [20-23]. Under conditions of nutrient homeostasis, IL-4 secreted by eosinophils maintains adipose tissue macrophages in an alternatively activated (M2) phenotype necessary for proper adipocyte function [24]. Disruption of this circuit, either through eosinophil depletion [22] or through abrogation of macrophage alternative activation [24-28], impairs adipocyte storage and endocrine functions, resulting in obesity-induced insulin resistance. While the exact nature of the macrophage-adipocyte signaling mechanism and the stimulus for tonic eosinophil IL-4 production remain unclear, these data demonstrate the intimate interdependence between adipocytes and leukocytes for proper tissue function and, importantly, show that disruptions in the tissue set point result in significant functional consequences for the tissue and the organism as a whole.

\section{Brown adipose tissue}

In contrast to white adipose tissue, brown adipose tissue has little role in long-term storage of energy but is critically required for acclimation to cold temperatures via a process termed adaptive thermogenesis [29-31]. This stems from brown adipose tissue's ability to oxidize fatty acids via uncoupled respiration, which generates heat rather than ATP in the respiring mitochondria [32]. Indeed, active brown adipose tissue is capable of impressive metabolic feats: the $63 \mathrm{~g}$ of brown adipose tissue present in an average adult human is estimated to catabolize $4.1 \mathrm{~kg}$ of white adipose tissue each year [33]. Until recently, it was believed that sympathetic nerves, which innervate brown and white adipocytes, coordinate metabolic responses to cold exposure [29,34]. However, Nguyen and colleagues demonstrated that increases in sympathetic tone are, in part, transmitted to white and brown adipocytes by alternatively activated macrophages [35]. Importantly, exposure of animals to progressively colder temperatures induces alternative activation of resident brown adipose tissue and white adipose tissue macrophages, resulting in catecholamine biosynthesis and norepinephrine release. These macrophage-derived catecholamines are required for cold-induced lipolysis in white adipose tissue and for inducing brown adipose tissue's oxidative and thermogenic capacity. Lastly, manipulation of the macrophage set point in brown adipose tissue and white adipose tissue through exogenous IL-4 supplementation or genetic abrogation of alternative activation is sufficient to enhance or impair thermogenesis, respectively [35]. As such, this unexpected interposition of macrophages within the 
thermogenic control circuit defines a mechanism by which resident brown adipose tissue and white adipose tissue macrophages support parenchymal cell function.

\section{Obesity}

While the rigidity and precision of tissue set points are necessitated by the tight physiologic constraints within which vertebrate tissues operate, the organism's survival under varying environmental influences necessitates constant physiologic adaptation (Figure 1). Tissue equilibria must then operate so as to counteract these influences and restore homeostasis. With obesity now an omnipresent global concern, the influence of environmental stress nutrient excess in particular - on white adipose tissue set points is the object of intense scrutiny. The primary behavioral feature of obesity is excessive dietary intake. As nutrient levels exceed homeostatic requirements, adipocyte hypertrophy and hyperplasia collaborate to buffer excess intake, while signs of cellular stress change the leukocyte set point $[18,36]$. Under these circumstances, adipose tissue macrophages increase from $~ 10 \%$ of white adipose tissue cellularity in lean animals to up to $50-60 \%$ in the obese [20], whereas the representation of eosinophils dramatically decreases in obese white adipose tissue [22]. Accordingly, there is a dramatic shift in the phenotypic set point: adipose tissue macrophages from lean animals demonstrate an alternative (M2) phenotype, whereas those from obese mice are classically (M1) activated, swapping the anti-inflammatory $\mathrm{M} 2$ phenotype for production of pro-inflammatory mediators [37]. The resulting phlogistic milieu has two metabolically salient effects. Firstly, it avidly recruits additional macrophages and other leukocytes to white adipose tissue and activates them along similarly inflammatory lines, reinforcing the new numerical and phenotypic set point [18]. Secondly, adipocytes and other metabolically critical cells (e.g. hepatocytes and skeletal muscle myocytes) are rendered insulin-resistant through direct abrogation of insulin signaling pathways in an effort to limit storage of excess nutrients and relieve cellular stress [38].

If nutrient intake returns to homeostatic levels - or metabolic demand increases proportionately - the original tissue equilibrium is reestablished [39]. If nutrient intake and expenditure are chronically mismatched, however, a new white adipose tissue set point is established, characterized by the familiar constellation of metabolic derangements that define the metabolic syndrome (Figure 1). While the wealth of mechanistic detail available is beyond the scope of this review [38,40,41], chronic lowgrade inflammation mediated by classical M1 adipose tissue macrophages emerges as the key pathophysiologic nexus responsible for the adverse health consequences of the new obese white adipose tissue set point $[7,18]$.

Figure I. Leukocyte set points dictate adipose tissue function

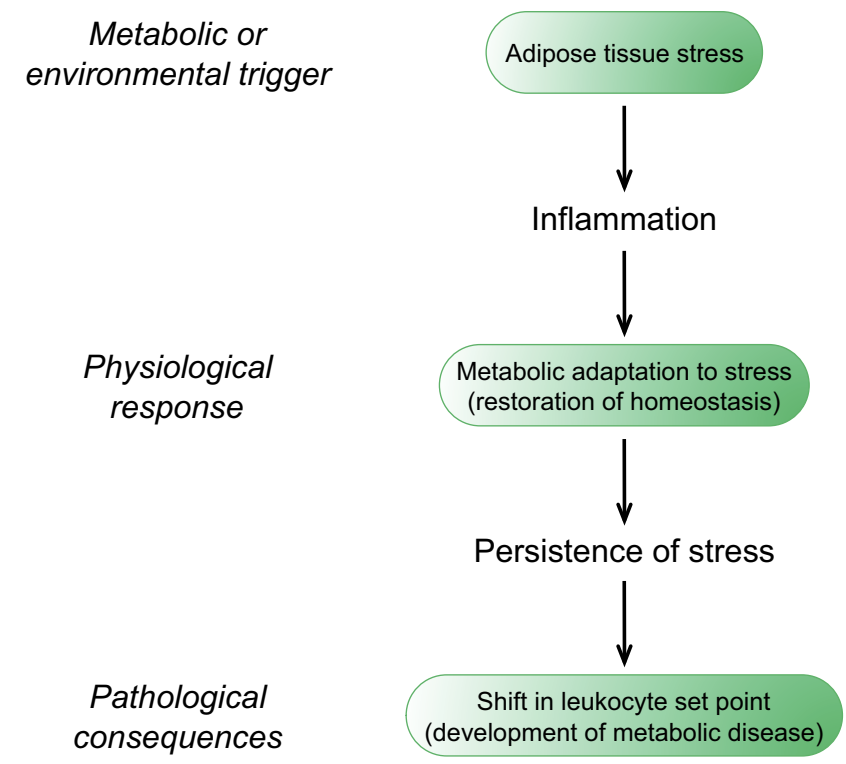

Adipose tissues of healthy mice contain a complement of leukocytes whose activation status or numbers change with metabolic or environmental stress. These transient inflammatory responses result in adaptations that restore metabolic homeostasis. However, in the setting of persistent metabolic or environmental stress, a new leukocyte set point is established for adipose tissue that amplifies inflammation, resulting in the various complications associated with obesity. 


\section{Tissue set points}

The wealth of literature on macrophages and other leukocytes in adipose tissue clearly defines functional roles for these cells in adipose tissue biology and establishes them as bona fide tissue constituents rather than immunologic transients. Just as clearly, the literature defines strict numeric and phenotypic relationships between various tissue constituents that correspond to specific physiologic states. The concept of population set points, however, is not limited to states of physiologic normality; the pro-inflammatory milieu of obese adipose tissue itself, once established, demonstrates temporal stability and resistance to change. As in lean adipose tissue, any perturbation of leukocyte set points, whether numeric or phenotypic, disrupts the tissue's new functional parameters [18].

The existence of distinct, defined, and non-arbitrary set points and their correlation with specific tissue phenotypes suggest a mechanism by which the organism can rapidly reprogram tissues to meet emerging environmental requirements. One example of such reprogramming is found in the vertebrate response to significant infectious challenge. This response involves the production, mobilization, and support of an impressive cellular immune response, the majority of which relies heavily on glycolytic metabolism [18]. As such, vertebrates have evolved an adaptive systemic insulin resistance to inflammation; infection-driven inflammation is an organism-wide signal to all non-essential tissues to dampen their insulin sensitivity, thus prioritizing glucose for use by the immune system, while alternative energy sources are mobilized [18]. Because of any given pathogen's inevitable proliferative advantage, the alacrity of this response is of the utmost importance. Therefore, pre-determined set points allow both rapid and accurate tissue recalibration and nutrient re-prioritization.

\section{Conclusion}

While significant progress has been made in defining leukocyte set points within adipose tissue with respect to obesity and insulin signaling, our understanding of leukocyte populations, phenotypes, and functional contributions in other tissues remains rudimentary. Indeed, our understanding remains incomplete even within adipose tissue: what defines a stable set point? How are pre-defined set points encoded? How may equilibria be manipulated to combat maladaptive shifts? Addressing these questions within adipose tissue offers the prospect of understanding how other complex tissues may adapt to changing environmental demands.

\section{Abbreviation}

$\mathrm{IL}$, interleukin.

\section{Competing interests}

The authors declare that they have no competing financial interests.

\section{Acknowledgments}

The authors thank Dr. Ruslan Medzhitov for openly sharing ideas about metabolic inflammation and macrophage set points. The author's work was supported by grants from: NIH (DK076760, HL076746, DK094641), Larry L. Hillblom Foundation Network Grant, Diabetes Family Fund (UCSF) and an NIH Director's Pioneer Award (DP1OD006415) to A.C. Due to the brevity of the review, we regret that we are unable to cite all relevant publications on this topic from our colleagues.

\section{References}

I. Flegal KM, Carroll MD, Ogden CL, Curtin LR: Prevalence and trends in obesity among US adults, 1999-2008. JAMA 20I0, 303:235-4I.

FI000 Factor 6

Evaluated by Ajay Chawla 14 Jun 2012

2. Finucane MM, Stevens GA, Cowan MJ, Danaei G, Lin JK, Paciorek CJ, Singh GM, Gutierrez HR, Lu Y, Bahalim AN, Farzadfar F, Riley LM, Ezzati M; Global Burden of Metabolic Risk Factors of Chronic Diseases Collaborating Group (Body Mass Index): National, regional, and global trends in body-mass index since 1980: systematic analysis of health examination surveys and epidemiological studies with 960 country-years and 9.1 million participants. Lancet 201 I, 377:557-67.

FI000 Factor 9

Evaluated by Manfred Müller 2 I Feb 20I I, Ajay Chawla I4 Jun 2012

3. Kumar V, Abbas AK, Aster JC, Robbins SL, "Robbins basic pathology." 9th edn. Philadelphia, PA: Elsevier/Saunders, 2012 [ISBN: 978-I4377I78I5].

4. Gordon S, Taylor PR: Monocyte and macrophage heterogeneity. Nat Rev Immunol 2005, 5:953-64.

FI000 Factor 8

Evaluated by Ajay Chawla 14 Jun 2012

5. Hume DA: The mononuclear phagocyte system. Curr Opin Immunol 2006, 18:49-53.

FI000 Factor 8

Evaluated by Ajay Chawla 14 Jun 2012

6. Gordon S, Fraser I, Nath D, Hughes D, Clarke S: Macrophages in tissues and in vitro. Curr Opin Immunol 1992, 4:25-32.

7. Medzhitov R: Origin and physiological roles of inflammation. Nature 2008, 454:428-35.

FI000 Factor 10

Evaluated by Ajay Chawla 14 Jun 2012

8. Van Rooijen N, Kors N, vd Ende M, Dijkstra CD: Depletion and repopulation of macrophages in spleen and liver of rat after intravenous treatment with liposome-encapsulated dichloromethylene diphosphonate. Cell Tissue Res 1990, 260:215-22.

FI000 Factor 6

Evaluated by Ajay Chawla 14 Jun 2012

9. Shi C, Pamer EG: Monocyte recruitment during infection and inflammation. Nat Rev Immunol 201 I, I I:762-74.

FI000 Factor 6

Evaluated by Ajay Chawla 14 Jun 2012 
10. Tremblay ME, Stevens B, Sierra A, Wake H, Bessis A, Nimmerjahn A: The role of microglia in the healthy brain. J Neurosci $201 \mathrm{I}$, 3I: I6064-9.

\section{FI000 Factor 6}

Evaluated by Ajay Chawla 14 Jun 2012

II. Pull SL, Doherty JM, Mills JC, Gordon JI, Stappenbeck TS: Activated macrophages are an adaptive element of the colonic epithelial progenitor niche necessary for regenerative responses to injury. Proc Natl Acad Sci U S A 2005, I02:99-104.

12. Ehninger $A$, Trumpp A: The bone marrow stem cell niche grows up: mesenchymal stem cells and macrophages move in. J Exp Med 20II, 208:42I-8.

13. Mosser DM, Edwards JP: Exploring the full spectrum of macrophage activation. Nat Rev Immunol 2008, 8:958-69.

14. Gordon S: Alternative activation of macrophages. Nat Rev Immunol 2003, 3:23-35.

15. Martinez FO, Helming L, Gordon S: Alternative activation of macrophages: an immunologic functional perspective. Annu Rev Immunol 2009, 27:45I-83.

FI000 Factor 6

Evaluated by Ajay Chawla 14 Jun 2012

16. Odegaard JI, Chawla A: Alternative macrophage activation and metabolism. Annu Rev Pathol 201 I, 6:275-97.

17. Stout RD, Suttles J: Functional plasticity of macrophages: reversible adaptation to changing microenvironments. J Leukoc Biol 2004, 76:509-13.

18. Chawla A, Nguyen KD, Goh YP: Macrophage-mediated inflammation in metabolic disease. Nat Rev Immunol 201 I, I I:738-49.

19. Rosen ED, Spiegelman BM: Adipocytes as regulators of energy balance and glucose homeostasis. Nature 2006, 444:847-53.

FI000 Factor 8

Evaluated by Ajay Chawla 14 Jun 2012

20. Weisberg SP, McCann D, Desai M, Rosenbaum M, Leibel RL, Ferrante AW, Jr.: Obesity is associated with macrophage accumulation in adipose tissue. J Clin Invest 2003, I I 2: I796-808.

21. Xu H, Barnes GT, Yang Q, Tan G, Yang D, Chou CJ, Sole J, Nichols A, Ross JS, Tartaglia LA, Chen $\mathrm{H}$ : Chronic inflammation in fat plays a crucial role in the development of obesity-related insulin resistance. J Clin Invest 2003, I | 2: | 82 |-30.

FI000 Factor 12

Evaluated by Giorgio Berton I4 Jan 2004, Ajay Chawla I5 Jun 2012

22. Wu D, Molofsky AB, Liang HE, Ricardo-Gonzalez RR, Jouihan HA, Bando JK, Chawla A, Locksley RM: Eosinophils sustain adipose alternatively activated macrophages associated with glucose homeostasis. Science 201 I, 332:243-7.

23. Feuerer M, Herrero L, Cipolletta D, Naaz A, Wong J, Nayer A, Lee J, Goldfine AB, Benoist C, Shoelson S, Mathis D: Lean, but not obese, fat is enriched for a unique population of regulatory $\mathrm{T}$ cells that affect metabolic parameters. Nat Med 2009, I 5:930-9.

FI000 Factor 7

Evaluated by Brigitte Huber 08 Sep 2009, Ajay Chawla 15 Jun 2012

24. Odegaard JI, Ricardo-Gonzalez RR, Goforth MH, Morel CR, Subramanian V, Mukundan L, Eagle AR, Vats D, Brombacher F, Ferrante AW, Chawla A: Macrophage-specific PPARgamma controls alternative activation and improves insulin resistance. Nature 2007, 447: I I I6-20.

25. Hevener AL, Olefsky JM, Reichart D, Nguyen MT, Bandyopadyhay G, Leung HY, Watt MJ, Benner C, Febbraio MA, Nguyen AK, Folian B, Subramaniam S, Gonzalez FJ, Glass CK, Ricote M: Macrophage PPAR gamma is required for normal skeletal muscle and hepatic insulin sensitivity and full antidiabetic effects of thiazolidinediones. J Clin Invest 2007, I I 7:1658-69.

26. Kang K, Reilly SM, Karabacak V, Gangl MR, Fitzgerald K, Hatano B, Lee $\mathrm{CH}$ : Adipocyte-derived Th2 cytokines and myeloid
PPARdelta regulate macrophage polarization and insulin sensitivity. Cell Metab 2008, 7:485-95.

27. Odegaard JI, Ricardo-Gonzalez RR, Red Eagle A, Vats D, Morel CR, Goforth MH, Subramanian V, Mukundan L, Ferrante AW, Chawla A: Alternative M2 activation of Kupffer cells by PPARdelta ameliorates obesity-induced insulin resistance. Cell Metab 2008, 7:496-507.

28. Liao X, Sharma N, Kapadia F, Zhou G, Lu Y, Hong H, Paruchuri K, Mahabeleshwar GH, Dalmas E, Venteclef N, Flask CA, Kim J, Doreian BW, Lu KQ, Kaestner KH, Hamik A, Clément K, Jain MK: Kruppel-like factor 4 regulates macrophage polarization. J Clin Invest 201 I, I 2 I:2736-49.

29. Lowell BB, Spiegelman BM: Towards a molecular understanding of adaptive thermogenesis. Nature 2000, 404:652-60.

30. Tseng YH, Cypess AM, Kahn CR: Cellular bioenergetics as a target for obesity therapy. Nat Rev Drug Discov 2010, 9:465-82.

31. Cannon B, Nedergaard J: Brown adipose tissue: function and physiological significance. Physiol Rev 2004, 84:277-359.

32. Nedergaard J, Bengtsson T, Cannon B: New powers of brown fat: fighting the metabolic syndrome. Cell Metab 20 I I, I3:238-40.

FI000 Factor 6

Evaluated by Ajay Chawla 15 Jun 2012

33. Virtanen KA, Lidell ME, Orava J, Heglind M, Westergren R, Niemi T, Taittonen M, Laine J, Savisto NJ, Enerback S, Nuutila P: Functional brown adipose tissue in healthy adults. N Engl J Med 2009, 360: $1518-25$

FI000 Factor 9

Evaluated by David Triggle 22 May 2009, Ajay Chawla I5 Jun 2012

34. Cannon B, Nedergaard J: Nonshivering thermogenesis and its adequate measurement in metabolic studies. J Exp Biol $201 \mathrm{I}$, 2 14:242-53.

35. Nguyen KD, Qiu Y, Cui X, Goh YP, Mwangi J, David T, Mukundan L, Brombacher F, Locksley RM, Chawla A: Alternatively activated macrophages produce catecholamines to sustain adaptive thermogenesis. Nature 201 I, 480:104-8.

FI000 Factor 18

Evaluated by P'ng Loke 06 Dec 20II, Joshua Milner 06 Dec 20II, Sebastian Amigorena and Olivier Joffre 31 Jan 2012, Alberto Mantovani 30 Apr 2012

36. Hotamisligil GS: Endoplasmic reticulum stress and the inflammatory basis of metabolic disease. Cell 2010, I40:900-I7.

37. Lumeng CN, Bodzin JL, Saltiel AR: Obesity induces a phenotypic switch in adipose tissue macrophage polarization. J Clin Invest 2007, I | 7: 175-84.

FI000 Factor II

Evaluated by Lionel Ivashkiv I4 Mar 2007, Ajay Chawla I5 Jun 2012

38. Hotamisligil GS: Inflammation and metabolic disorders. Nature 2006, 444:860-7.

FI000 Factor II

Evaluated by Marc Jeschke 25 Apr 2008, Ajay Chawla 15 Jun 2012

39. Kosteli A, Sugaru E, Haemmerle G, Martin JF, Lei J, Zechner R, Ferrante AW, Jr.: Weight loss and lipolysis promote a dynamic immune response in murine adipose tissue. J Clin Invest 2010, 1 20:3466-79.

FI000 Factor 6

Evaluated by Ajay Chawla 15 Jun 2012

40. Olefsky J, Glass C: Macrophages, Inflammation, and Insulin Resistance. Annu Rev Physiol 2010, 72:1-28.

FI000 Factor 6

Evaluated by Ajay Chawla 15 Jun 2012

4I. Shoelson SE, Lee J, Goldfine $A B$ : Inflammation and insulin resistance. J Clin Invest 2006, I I 6: I 793-80I. 